\title{
A Case Of A Uniocular Pterygium Related To An Unusual Occupation
}

\author{
M Woodcock, J Huntbach, R Scott
}

\section{Introduction}

A Pterygium is a characteristic triangular shaped fibrovascular growth of conjunctival and subconjunctival tissue, which invades the cornea between the epithelium and Bowman's layer at its apex. Pterygia occur within the intrapalpebral space and are more common on the nasal rather than temporal side. They have three components: the cap, a grey avascular zone that precedes the head of the lesion surrounding it like a halo; the head, which is white and slightly elevated; and the body, which is a flat sheet of pink, highly vascularised connective tissue. When the pterygium is actively growing the tissue is red and inflamed but as the lesion becomes inactive the vascularity diminishes and the redness disappears. They tend to occur on the medial aspect of the cornea and are more common in people who live or have lived in hot, dry climates.

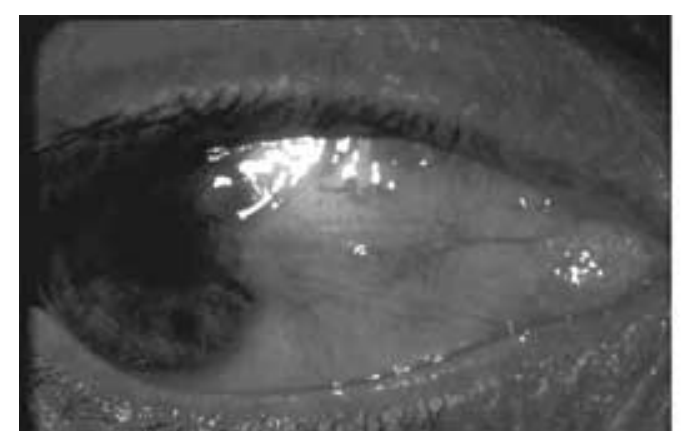

Illustration of both eyes in the abducted position showing a pterygium encroaching on the medial aspect of the right cornea and the absence of a pterygium on the corresponding area of the left cornea.

\section{Case Report}

A 30-year-old right-handed white man originally from Zimbabwe was serving as a sniper in the Royal Marines. He was seen in one of the eye departments of the Defence Secondary Care Agency with a 2 year history of a progressively enlarging pterygium on the bulbar conjunctiva of the nasal aspect of his right eye. This had recently started to enlarge and he found it unsightly. Unusually the corresponding conjunctiva of his left eye appeared healthy. As part of his job he works with a patch over his left eye with his right eye open, exposed at the rifle sight for several hours at a time. Much of this time has been spent in hot dusty environments.

Most pterygia do not require any form of treatment but those that become problematic can be removed surgically. This maybe indicated for a number of reasons.
Firstly, as they are mildly raised, they can interfere with the normal wetting of the eye causing local irritation and discomfort. As they enlarge they may also begin to encroach on the visual axis of the eye (though they never involve more than half of the cornea). Finally, patients sometimes find them unsightly and want them removed for cosmetic reasons. There is, however, a significant recurrence rate after surgery with an estimated $40 \%$ reappearing (1). Reduced recurrence rates are seen where the excision is augmented with other strategies: Beta irradiation to the area of excision $(20-23 \%)(1,2)$; the use of intraoperative or post-operative mitomycin C (4-12.5\%) (2-4); and limbal conjunctival stem cell autograft $(14.6 \%)$ (3). This man's pterygium was excised and the exposed area replaced with a transplanted free conjunctival autograft, which produced a good cosmetic result at 6 months.

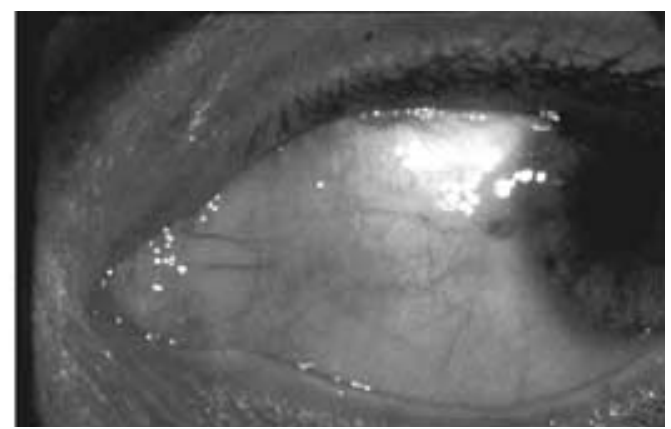

The provisional diagnosis was confirmed by histological examination of the excised tissue, which showed a subepithelial fibrovascular mass with characteristic fragmentation and basophilic change. This appearance is described as elastoid degeneration because the degenerated collagen will stain positively with a histochemical stain for elastic fibres, such as the Verhoeff-van Gieson stain. However, pre-treatment of the samples with an elastase does not diminish the staining.

Table 1. Treatment Options.

\begin{tabular}{|l|l|}
\hline Excision & Bare Sclera \\
\hline & Conjunctival Autograft - Rotational flap \\
- Free flap
\end{tabular}




\section{Comment}

Pterygia tend to occur in people who live or have lived in hot, dry climates. They occur most frequently in populations living near the equator (the nearer the equator, the greater the prevalence) and are more common with advancing age (5). The geographical distribution of pterygia along with their anatomical location in the intrapalpebral region implicate the environment as a cause and they are thought to develop in response to chronic dryness and/or excessive exposure to ultraviolet light $(6,7)$. The first sign of corneal invasion is a line of fibroblasts between the epithelial basement membrane and Bowman's layer, an acellular layer of interwoven collagen fibrils immediately beneath the epithelial basement membrane. The fibroblasts follow this plain into the cornea later guiding the bulky fibrovascular tissue along the same path. The stimulus for this invasion is felt to be solar radiation induced degenerative changes in the basal (stem) cell layer, or the result of an immunological response to altered basement membrane material (8). It is suggested that internal reflection from the side of the nose and the orbital margin causes ultraviolet light to be focused onto the medial limbus, where corneal epithelial stem cells are affected (9).

The patient in this case was born and brought up in Zimbabwe where there is a higher prevalence of pterygium than in Western Europe. He is unusual, however, in that people with pterygia generally have them on both eyes, although they may progress asymmetrically. As part of his occupation within the military he has spent many hours with his right eye exposed at the rifle sight and his left eye patched, protected from the elements. Furthermore it is well known that during periods of intense concentration the blinking rate is reduced allowing increased tear evaporation and subsequent exposure. On this basis we feel that this man's uniocular pterygium formed as a result of his occupation.

\section{References}

1. Tasman W, Jaeger GA. Duane's Clinical Ophthalmology. Lippincott: 1991;Vol. 4 Chapter 16.

2. Amano S, Motoyama Y, Eguchi S, Eguchi K. Comparative Study of Intraoperative Mitomycin C and Beta Irradiation in Pterygium Surgery. $\mathrm{Br} \mathcal{F}$ Ophthalmol 2000 Jun; 84 (6): 618-21.

3. Cardillo JA, Alves Mr., Ambrosio LE, Poterio MB, Jose NK. Single Intraoperative Application Versus Postoperative Mitomycin C Drops in Pterygium Surgery. Ophthalmology 1995 Dec; 102 (12): 1949-52.

4. Mutlu FM, Sobaci G, Tatar T, Yildirim E. Ophthalmology 1999 Apr; 106 (4): 817-21.

5. Cameron ME. Pterygium Throughout the World. Springfield: Charles C. Thomas, 1965.

6. Threlfall TJ, English DR. Sun Exposure and Pterygium of the Eye: A Dose-Response Curve. American Fournal of Ophthalmology 1999; 128(3):280-7.

7. McCarthy CA, Fu CL, Taylor HR. Epidemiology of Pterygium in Victoria, Australia. Br. $\mathcal{F}$. Ophthalmology 2000; 84:289-292.

8. Casey TA, Sharif KW. Corneal Dystrophies and Degenerations. Wolfe: 1991 Chapter 9.

9. Kwok LS, Coroneo MT. A Model of Pterygium Formation. Cornea 1994;13:219-224. 